\title{
Death Anxiety and Meaning of Life in the Three Groups of Nurses: Obstetrics and Gynecology and CCU Nurses and Housewives
}

\author{
Faeze Khanlarzade \\ Master of Clinical Psychology in Literature Factualty, Islamic Azad University of Najaf abad, Isfahan, Iran \\ Faeze.khanlarzade@gmail.com \\ Batool Rezaei \\ Master of Curriculum Development, Factulty of Edjucational Science and Psychology in \\ Islamic Azad University of Marvdasht, Yasuj, Iran; Btrezaei66@gmail.com \\ Nezamaddin Ghasemi \\ Ph.D in Psychology, Assistant Professor, Salman Farsi University of Kazerun \\ Nezamghasemi@yahoo.com \\ Hakime Aheste \\ Master of Social Science in Allame Tabatabaie university, Tehran, Iran; Haheste@yahoo.com \\ The aim of this study is to compare the anxiety of death and the meaning of life in three groups of nurses: obstetrics and \\ gynecology and CCU nurses and housewives. Documentary and survey methodologies were used. The purpose of this \\ research was applied in terms of objective and used a descriptive-comparative research design. 30 nurses of CCU ward, 30 \\ nurses in the maternity ward, as well as 30 housewives were analyzed in three groups on a scale of meaning of life and death \\ anxiety. For data analysis, two-way ANOVA was used, and the results of the study showed that there was a significant \\ difference between ICU nurses, maternity nurses and housewives in terms of death anxiety and meaning of life.
}

Doi:10.5901/mjss.2016.v7n2s2p18

\section{Abstract}

Keywords: death anxiety, meaning of life, nurses

\section{Introduction}

Although humans, like other creatures, experience birth, illness, youth, maturity, old age and death, but the only man knows he will die one day and tries to take certain measures to himself protect against destruction (Elijah. Translation: Mehregan \& Najafi, 2006). But death is not a separate phenomenon from outside the realm of life. Death is not an accident, but is a law in place from the beginning of life. So one has to think about death and try to understand it. Fear of death is not a fear of the unknown, but this fear comprises many other fears of the life that are reflected in deprivation and failure (Mo'tamedi, 2007).

The death expectation is not far expectation waiting at the end, but it is a hidden anxiety creeping in the senses to the extent that death is felt in everything. Death anxiety is a term used for imagining and understanding the knowledge of death. Psychological Science in the $21^{\text {st }}$ century has noticed that a man should spend his intellectual energy on the positive aspects of his experience (Seligman \& Csikszentmihalyi, 2000). According to Feifel (1990) since the beginning of recorded human history, the truth of death and human limitations have been a strong concern and the most shocking force and has become one of the most unpleasant features of human history and marking his inability in the face of the future and the death (Feifel, 1990). Although the death is a biological and psychological reality and feelings about death and dying process is rooted in the socialization of the individual, but because thinking about death is horrifying, most people prefer not to think about it (Gailliot, 2006).

Because it reminds human vulnerability to death despite technological advances, anxiety and fear of death reminds unpleasant and common experience for people (Abdel-khalek, 2002). The fear of death is a kind of anxiety in the field of 
psychiatry. Bolski considered it as thoughts, fears and emotions related to the event beyond the normal life and about the end of life. Harmon Jones knows it consciously or unconsciously of death. Death anxiety is a feeling of lack of pleasure in life and death and a person who suffers from anxiety, life for him is not a pleasure and he has a sense of the absurdity (King, 2008). One way to reduce the anxiety and fear of death is turning to religion and religious tendencies, and it has been shown that in those who have negative attitudes to religion, fear of death increases (Thorson and Powell, 2000). Historically meaningful life is one of the most controversial concepts in philosophy and psychology. Trying to understand its nature has continued over the centuries, philosophers, psychologists and psychiatrists such as Kierkegaard, Nietzsche, Camus, Sartre, Frankel, May, Yalom have to discuss and think about it. Despite comprehensive attempts, yet many unanswered questions about the nature of it have remained, for example, what is meaning of "meaning of life", what is the nature "meaning" (Feldman and Snyder, 2005). The research on positive psychology and well-being is increasingly growing. Subjective well-being is an important construct in research related to the interpretation of the character and is defined as a positive evaluation of the balance between positive affect and negative affect (Deiner and Oishi, 2003; Yee Ho and Cheung, 2007). One of the constructs that were developed in recent years and was considered as an indicator of well-being is the meaning of life, the meaning of life is defined differently in different areas, and because of the lack of the global definition of the meaning of life suiting everyone, and every person should find a meaning for his life.

Today, in the medical environments of various countries, we see nurses do not want to continue nursing and instead want to engage in non-nursing jobs, have the desire to leave their job, make early retirement requests, make complaints of excessive workload and a lack of human resources and in the meantime, in intensive care units including ICU \& CCU as well as dialysis and oncology this problem becomes more strong and the anxiety and stress is more significant compared to other wards (Sutherland and Cooper, 1997). Researches have shown that regular encounters with patients, having responsibility for human health, clinical processes, dealing with dying patients, dealing with emergency situations and emergencies among nurses can reduce performance and affect their physical and mental health (Greenied,Jim \& Roger, 2005). Despite the importance of death anxiety and the meaning of life, it is considered a taboo in our country and meet resistance, so that research in this area so far has not happened in our country and even in Europe and the United States only in the last two decades, little has been done in this respect. Therefore this study needed to be performed.

\section{Theoretical Framework}

\subsection{The concept of death anxiety}

Jones, Simon Greenberg, Pizinski, Solomon et al. defined death anxiety as conscious and unconscious fear of death or dying. Death Anxiety is a complex concept that is not easily explained and generally include concepts of fear of death oneself and others. In other words, anxiety and fear of death is the prospect of death of oneself and the important people in one's life (Gire, 2002). Although the death of a biological and psychological facts and feelings about death and dying process is rooted in the socialization of the individual in society, but the thought of death is frightening and most people prefer not to think about it, because death shows vulnerability of human despite technological progress and anxiety and fear of death are the unpleasant experience of human beings (Mennin et al., 2009). Usually meaning in life points to a sense of existential integration that seeks answer to what life is, and seeks to understand the purpose of life and achieve worthwhile goals and thus achieve complete sense and usefulness (Yee Ho et al., 2010). Steiger and Frazier (2006) believed the meaning of human life had an effect on the sense of constructiveness of the human and even claimed that the nature of man and his existence depends on having such a concept. Death anxiety includes thoughts, fears and emotions associated with the end of life. (Bolski, 1999), this type of anxiety is a multidimensional concept, in this regard, Walter and Stein (2007) enumerated eight dimensions therefor: 1- fear of the process of dying, 2- fear of premature death, 3- fear of death of loved ones, 4-phobias of death, 5- fear of ruin, 6- fear of body after death 7- fear of unknown nature of death, and 8 - fear of the dead.

Kastenbaum (2000) having made a brief review of research in non-clinical population showed that death anxiety is a common phenomenon among the general population. In this regard, Agras (1996) reported that 16 percent of people have death anxiety and phobic anxiety in this regard Women have higher levels of death anxiety than men. The higher the educational level and socioeconomic status, the lower level of death anxiety and the higher the level of religious beliefs and participation in religious activity, the lower the death anxiety.

The concept of the meaning of life:

The meaning of life is an issue that has preoccupied the minds of great thinkers in human history. Meanwhile, the 
search for the meaning of life can be done by all human beings at any level. Everybody's perception of disease depends on his/her perception of human nature. On the one hand it can be based on naturalistic approach the man described in Biological Sciences and the disease is defined as a biological function and on the other hand it can be used to describe the emotions, moods, hopes and aspirations based on mental aspects. Merely empirical and naturalistic treatment of human disease is incomplete because it does not include the whole human nature. Because human is a sentient, conscious being and is able to choose and he may not be considered like a broken down car when he is sick and the anxiety and depression are not merely unpleasant symptoms that a doctor must eliminate, but they may suggest that one needs to modify his approach to life. The meaning of life is a multidimensional construct that can be understood in different ways and in general, it refers to the value and purpose of life and for some, it refer to spirituality. In order to evaluate the meaning of life in this study, the meaning of life scale of Steger was used.

Baumeister (1991) stated that sense of meaning realizes through the fulfillment of basic needs for the targeted efficiency and self-esteem and other researchers noted that the realization of meaning is associated with practical significance and daily decision making.

In another definition, the meaning of life refers to a sense of connection with the Creator, having a purpose in life, pursuit and achievement of the worthy ends and evolution. The meaning of life has essentially a cognitive nature, because it involves people's beliefs about the existence of an ultimate purpose in life, spirituality and belief in the afterlife (Ho MY et al., 2010). In fact, the meaning of life is one of the predictors of well-being and satisfaction with life Halama \& Dedova, 2007, Ho MY et al., 2010).

\section{Methodology}

Survey-documentary method was used. The purpose of this research was applied and had a descriptive- comparative research design. 30 nurses of CCU ward, 30 nurses in the maternity ward, as well as 30 housewives were analyzed in three groups on a scale of death anxiety and meaning of life. To examine the impact of variables, using a questionnaire, data is collected. Information needed for our research is collected through a written questionnaire. In this study, information required was obtained using library and field methods. And data analysis was conducted using two-way ANOVA.

\section{Research Tools}

\subsection{Death anxiety scale / Templer}

This questionnaire has 15 items and 5 dimensions. Scoring method is that for each correct choice, 1 point is assigned, and for each incorrect choice, score 0 is considered. However, this method of scoring in questions 10, 11, 12, 13, 14 and 15 is reversed. To get the score for each dimension, the scores for individual questions related to that dimension are summed.

\section{Reliability and Validity}

Tavakoli et al. (2011) examined the reliability and validity of Templer's death anxiety. The validity of the questionnaire was obtained to be 0.87 using test - retest. Content and face validity of the questionnaire has been accepted by experts.

Scale of meaning of life of Steger \& Frazier, Oishi \& Color MLQ

Scale of the meaning of life by Steger, frazier, Oishi \& Color (2006) was used for evaluation of existence of meaning and attempt to find meaning and validity and reliability and factor structure have been examined in different studies with different samples.

\subsection{The First Hypothesis}

There is a relationship between three groups of CCU nurses, maternity ward nurses and housewives in terms of the meaning of life. 
Table 1 - Mauchly's test of sphericity for component of meaning of life

\begin{tabular}{|l|c|c|c|c|}
\hline Effect of internal subject & Mauchly & App. X² & DOF & Sig. \\
\hline Intragroup & .976 & .667 & 2 & .316 \\
\hline
\end{tabular}

In table of Mauchly's Test of Sphericity test uniformity of variance - covariance and variance-covariance matrices was tested and at the significant level of 0.316 no reason for the lack of uniformity in the components of meaning of life among the nurses was found.

Table 2 - Two-way analysis of variance test for the intra-group impact of component of meaning of life

\begin{tabular}{|l|l|c|c|c|c|c|}
\hline \multicolumn{2}{|l|}{ Source } & Sum of squares & DOF & Mean square & F statistic & Sig. \\
\hline Meaning of life & Sphericity Assumed & 130.956 & 2 & 157.478 & 4.137 & 0.000 \\
\cline { 2 - 7 } & Greenhouse-Geisser & 130.956 & 1.954 & 157.842 & 4.137 & 0.000 \\
\cline { 2 - 7 } & Huynh-Feldt & 130.956 & 2.000 & 157.478 & 4.137 & 0.000 \\
\cline { 2 - 7 } & Lower-bound & 130.956 & 1.000 & 300.956 & 4.137 & 0.000 \\
\hline
\end{tabular}

The most important variance analysis table above is the Tests of Within-Subjects Effects table. In the first row of the significant level of variance analysis, the significance level is 0.000 . This means that the there is a significant difference between nurses of maternity ward, CCU ward and housewives in terms of components of meaning of life. And this is true also in the next rows where more conservative tests are provided.

\subsection{The Second Hypothesis}

There is a relationship between death anxity of three groups of CCU nurses, maternity ward nurses and housewives.

Table 3 - Mauchly's test of sphericity for component of death anxiety

\begin{tabular}{|l|c|c|c|c|}
\hline Effect of internal subject & Mauchly & App. X2 & DOF & Sig. \\
\hline Intragroup & .987 & .371 & 2 & 0.665 \\
\hline
\end{tabular}

In table of Mauchly's Test of Sphericity test uniformity of variance - covariance and variance-covariance matrices was tested and at the significant level of 0.465 no reason for the lack of uniformity in the components of death anxiety among the nurses was found.

Table 4 - Two-way analysis of variance test for the intra-group impact of component of death anxiety

\begin{tabular}{|l|l|c|c|c|c|c|}
\hline Source & sum of squares & DOF & Mean square & F statistic & Sig. \\
\hline Death anxiety & Sphericity Assumed & 540.622 & 2 & 120.311 & 3.047 & 0.000 \\
\cline { 2 - 7 } & Greenhouse-Geisser & 540.622 & 1.974 & 120.578 & 3.047 & 0.000 \\
\cline { 2 - 7 } & Huynh-Feldt & 540.622 & 2.000 & 120.311 & 3.047 & 0.000 \\
\cline { 2 - 7 } & Lower-bound & 540.622 & 1.000 & 140.622 & 3.047 & 0.000 \\
\hline
\end{tabular}

The most important variance analysis table above is the Tests of Within-Subjects Effects table. In the first row of the significant level of variance analysis, the significance level is 0.000 . This means that the there is no significant difference between nurses of maternity ward, CCU ward and housewives in terms of death anxiety. And this is true also in the next rows where more conservative tests are provided.

\section{Discussion and Conclusion}

The results of this study to compare the anxiety of death and meaning of life in three groups of nurses: maternity and 
CCU nurses and housewives showed that death anxiety is significantly different in the three groups; also as for the meaning of life components, there was is a significant difference among the three groups. It can be said that housewives has less death anxiety because they are exposed to a less stressful environment and due to dealing with instances of death of patients in a month, death anxiety increases among nurses, and this to some extent has an impact on their meaning of life. In explaining the findings, we can provide several points. First, meaning therapy will help the clients to find a goal or goals for their lives. Having a goal makes the life meaningful through reviving creative values, in light of the work, service to others or restoring the experiential and trending values (particularly among nurses of maternity ward and housewives). In this case, the person who has chosen to achieve a purpose will make constant effort. The struggles in life gives happiness and joy and eliminates sense of despair and futility. Also, it creates a sense of competency created and makes the life meaningful. Other reasons for effectiveness of meaning therapy is to help clients deal with the reality of death. Awareness of death increases sense of responsibility of people towards living. The result is that people with knowledge of death make all their efforts to fulfill their responsibility to all the moments of life. The awareness of unavoidable death increases the eager to perform challenging and risky activities. Awareness of death gives the clients the opportunity who know the defects to still live bravely.

\section{References}

Elias, N. (2006). The Loneliness of the Dying. O. Mehregan, S. Najafi, Tehran: Game Now.

Motamedi, G. (2007). Man and Death: An introduction to death study. Tehran: Nashre Markaz.

Deiner,E., Oishi,S., \& Lucas,R.E. (2003). Personality, culture and subjective wellbeing: Emotional and cognitive evaluation of life. Annual Review of Psychology,54,403- 425.

Baumister,R.F.,\& Newman,L.S.(1991). How stories make sense of personal experience: Motives that shape autobiographical narratives, Personality and Social Psychology Bulletin,20,676-690.

Greenied S., Jim P.(2001). Roger H.The anxieties of male and female medical students on cosmmencing clinical studies:The Role of gender. Education of Health 2001,14(1):718-730.

Feifel H.(1990). Psychology and death: Meaningful rediscovery. Ame Psychol; 1990. 45: 537-543.

Abdel-khalek,A\&Lester,D.(2006).optimism and pessimism in kuwaiti and American college students.international journal of social psychiatry.Vol.52(2);110-126.

Kastenbaum, R. (2000). The psychology of death(3rd ed). New York: Springer

Feldman, D. B.; Snyder C. R. (2005) "Hope and the Meaningful Life: Theoretical and Empirical Associations between Goal-directed Thinking and Life Meaning", Journal of Social and Clinical Psychology,24, 401-421.

Gire, J. T (2002). How death imitates life: Cultural influences on conceptions of death and dying. In: W.J. Lonner, D.L. Dinnel, S. A. Hayes, \& D.N. Sattler (Eds.). Online Readings in Psychology and Culture.

Mennin, D.S., McLaughlin, K.A., \& Flanagan, T.J. (2009). Emotion regulation deficits in generalized anxiety disorder, social anxiety disorder, and their cooccurrence. Journal of Anxiety Disorders, 23,866-871.

Yee Ho,M.,Cheung,F.M., \& Cheung,S.F. (2010). The role of meaning in life and optimism in promoting subjective well-being. Personality and Individual Difference,48,658-663.

Seligman,E.P.,\& Csikszentmihalyi,M.(2000). Positive psychology:An introduction. American Psychologist,5,14-55.

King, D. B. (2008). Rethinking claims of spiritual intelligence: A definition, model, and measure. Unpublished Master's Thesis, Trent University, Peterborough, Ontario, Canada.

Thorson. J. A. and Powell, F.C. (2000). Death anxiety in younger and older adults. In a. tamer, editor, death attitudes and the older adults, theories, concepts and applications, burner- rout edge, Ledge Philadelphia, 123- 136.

Steger, F. M \& Frazier, $P,(2006)$. The meaning in life questionnaire: assessing presence of and search for meaning in life. Journal of Counseling Psychology, 53, 80-93.

Yee Ho, M; Cheung, F. M \& Cheung, S. F,(2010). The role of meaning in life and optimism in promotiong well - being. Personality and Individual Differences. Pages 658- 66. 